\title{
Defensive medicine practice and effect on healthcare expenditures and tort reform
}

\begin{abstract}
Healthcare reform is of much debate in this country especially in the current economic climate. This review is based on research from many different scholarly groups. The call for reform is directly derived from skyrocketing healthcare costs. The United States spend about $50 \%$ more on healthcare than any other nation. Studies have estimated that the cost of defensive medicine is around $\$ 100-180$ billion each year. Defensive medicine not only is costly to the healthcare system, but this practice overburdens the system with excessive testing and procedures taking available resources away from patients who might actually need it. The vast majority of the research reviewed has shown that defensive medicine is a widespread and costly problem. To avoid malpractice, the physicians need to simply follow standards of care needed for each individual patient. Tort reform is also in much debate in this country. Many studies have been conducted on this topic with mixed results. The call for tort reform includes but is not limited to: Gaps on noneconomic damages, punitive damages, shorter statutes of limitations, expert witness qualifications, attorney fee caps, patient compensation funds, and no-fault programs. The majority of the research indicates that tort reform in the form of limiting malpractice payments significantly reduces the frequency and severity of malpractice claims. It also lowers malpractice insurance premiums. States like Texas and Mississippi that have some sort of tort reform have recognized malpractice insurance rate cuts as high as $17 \%$ after tort reform.
\end{abstract}

Volume 6 Issue I - 2019

\author{
Adam C Schneider \\ Southern Illinois University Edwardsville, USA
}

Correspondence: Adam C Schneider, DNP(c) CRNA, Southern Illinois University Edwardsville, USA, Tel 8153889598, Email adschne@gmail.com

Received: January 01, 2019 | Published: February 13, 2019

Keywords: defensive medicine, tort, reform, cost, healthcare

\section{Introduction}

The recent economic climate has brought about new healthcare reform ideas due to the increase in the price of healthcare. The associated cost of these new reform ideas is in much debate. An important area in healthcare to investigate is one of healthcare reform pertaining to defensive medicine practices and their cost implications on our current healthcare system. It is important to know the meaning of defensive medicine in order to judge if it is a problem, if it has significance in the medical field, and if there are any solutions to this issue. Defensive medicine is defined by ${ }^{1}$ as the practice of ordering medical tests, procedures, or consultations of doubtful clinical value in order to protect the prescribing physician from malpractice suits. Defensive medicine can also be defined by a deviation from sound medical practice that is induced primarily by a threat of liability Studdert et al. ${ }^{2}$

The people of the United States spent \$5,267 per capita for health care in $2002 .{ }^{3}$ This is $53 \%$ more than the second highest country which is Switzerland. The U.S. spent $\$ 3,074$ more than the average country in the world. Two possible reasons for the differential are supply constraints that create waiting lists in other countries and the level of malpractice litigation and defensive medicine in the United States. ${ }^{3}$ Studies have estimated that the cost of defensive medicine is $5-9 \%$ of the United States health care budget which is $\$ 2$ trillion annually or \$100-180 billion each year. ${ }^{4}$ These numbers do not take into account the amount of money consumers pay for tests, lab results, and appointments in which the government does not contribute. One study indicates that defensive medicine conservatively cost $\$ 1.4$ billion in Massachusetts alone. ${ }^{5}$ Not only is healthcare in the United States the most expensive in the world, but it is growing at an alarming rate. From 1980-2006 the percentage of healthcare expenditures compared to the Gross domestic product increased from 8.5-15\%. ${ }^{6}$ Some focal questions for this research include: What is the prevalence of defensive medicine in current practice? What is the cost of defensive medicine? Can tort reform have a positive impact to lower the cost of healthcare and if so, what types of reform are needed?

\section{Discussion of literary review}

The causes of defensive medicine include fear of a misdiagnosis which leads to litigation and also patient demands. Patients naturally want best and the newest types of care available. The newest technology also comes with a hefty price tag. Demanding this technology usually will drive up the cost of healthcare. ${ }^{2}$ Furthermore, patients who insist on certain test get indulged even if the test is not needed since doctors are apprehensive about being sued. ${ }^{7}$ According to a recent study in Pennsylvania, 93\% of responding physicians reported that they had performed some type of defensive medicine. ${ }^{4}$ Of the $93 \%$ of physicians reporting defensive medicine, $43 \%$ reported imaging technology was most overused. Overuse of imaging technology can lead exposure to radiation and possible allergic reactions to contrast dye (Healthcare Risk Management, 2009). ${ }^{5}$ Defensive medicine can also lead to patients not receiving necessary tests. Doctors stated that they avoided procedures that were slightly risky for patients even if the procedure was warranted because of their fear of litigation. ${ }^{4}$

A similar study was conducted in Massachusetts mirroring the Pennsylvanian study's results. Physicians reported that $83 \%$ practiced defensive medicine and that $18-28 \%$ of the tests, procedures, referrals and consultations were done defensively. ${ }^{5}$ The Massachusetts study covered $46 \%$ of the physicians in the state. Similarly to the Pennsylvania and Massachusetts studies, Sloan et al. ${ }^{8}$ found that $59 \%$ of physicians ordered more tests than medically relevant and this 
figure rated to $70 \%$ among physicians in emergency rooms Sloan et al. ${ }^{8}$ According to the Agency for Healthcare Research and Quality, missed heart attacks are one of the most frequent reasons for medical malpractice in adults. Low-risk heart attack patients cause more concern for emergency malpractice than any other. This practice of defensive medicine once again leads to more hospitalization and greater use of diagnostic test which increases the cost of healthcare. ${ }^{6,9}$

In an article by John De Weese, ${ }^{10}$ he described an example of defensive medicine. He introduces the idea of defensive practices concerning typical fibrous cortical defects that are common on radiograph reports. These benign growths have been ignored for years but it has been increasingly common for Radiologists to add a cautionary statement to their reports. For example, Radiologists could now state "benign-appearing lesion but clinical correlation is recommended by the use of MRI and CT scanning". ${ }^{10}$ By adding a cautionary sentence to the report, no matter how unlikely the defect could transform into a problem, the Radiologist will be completely blameless. ${ }^{10}$ The chain of defensive medicine can now continue to the Physician requesting the radiograph. The cautionary sentence by the Radiologist leads to the Physician who must now order expensive testing and follow-ups simply to deter from legal action.

The United States malpractice system is based on tort law. ${ }^{10}$ Tort law holds physicians responsible for not harming patients intentionally or through neglect. Medical malpractice was made to compensate patients injured through negligence, promote justice for injured patients and to provide appropriate incentives for healthcare professionals to supply safe and efficient care. One study states that if the risk of malpractice lawsuits causes the level of care to exceed the normal standard of care then that it is an extremely costly side affect of tort law Slone et al. ${ }^{8}$ According to Luce $^{11}$ the costs of the malpractice system may trigger defensive medicine practices and consequently increase healthcare costs. The most damaging attribute of our medical malpractice system is not that it fails to compensate victims or to deter poor performance but that it promotes the practice of defensive medicine..$^{12}$ Moreover, defensive medicine is a side effect of our current medical liability crisis.

Lawmakers have focused tort reform but not limited to: Gaps on noneconomic damages, punitive damages, shorter statutes of limitations, expert witness qualifications, attorney fee caps, patient compensation funds, and no-fault programs. ${ }^{13}$ This literary review looked at which states currently have malpractice caps compared to which did not and the cost implications of these caps. There are currently 28 states that have some sort of malpractice reform to reduce the severity of claims Hellinger et al. ${ }^{12}$ These states with tort reform had an increase in physicians by $2.4 \%$ in 2002 Gorombei et al. ${ }^{14}$ The maximum payout in states with medical malpractice caps ranged from $\$ 250,000$ to $\$ 1,000,000$. The median payout for medical damages was $\$ 110,000$ in 2002 compared to $\$ 60,000$ in 1991 showing an alarming $83 \%$ increase over that time period. States with caps had a $15.7 \%$ lower average payout than those states without caps Gorombei et al. ${ }^{14}$ According to Slone et a $1 .{ }^{8}$ types of tort reform can be classified as indirect and direct. Punitive damage and noneconomic damage caps are types of indirect reform and are the single most effective methods of reducing healthcare costs. ${ }^{13}$

A nationwide study found that the most direct connections between reform measures and a reduction in insurance company losses came from just two tort reform measures, punitive damage and noneconomic damage caps Karno et al. ${ }^{13}$ It was found that in states that introduced punitive damage reform had a $6 \%-7 \%$ less loss than states without punitive damage reform. In states that do not allow punitive damages to be awarded, they found $15 \%$ lower losses compared to states that allow punitive damage. Similarly, the states that did not permit the insurability of punitive damages saw a $6 \%-7 \%$ reduction in losses as compared to states that did allow this type of insurance Karno et al. ${ }^{13}$ This pattern of cost reduction continued with caps on noneconomic damages. The states that passed caps on noneconomic damages into law saw a $16 \%-17 \%$ reduction in loss as compared to states that did not impose caps Karno et al. ${ }^{13}$ A 2009 analysis from the Congressional Budget Office estimates that government health care programs could save $\$ 41$ billion over 10years if nationwide limits on jury awards for pain and suffering were made into law.

A direct correlation with malpractice caps and lower insurance premiums can be seen in Texas. In 2003, Texas passed into law a $\$ 750,000$ limit on noneconomic damages and instituted punitive damages reform. ${ }^{2}$ This law was reviewed in 2005 finding that the state's five largest physician insurers cut rates, the largest of the cuts were by $17 \%$, and the state's largest hospital insurer cut rates by $15 \%$. Similarly in Mississippi, in 2004 they established punitive damages caps based on the net worth of the defendant and set noneconomic caps on medical cases at $\$ 500,000$ Karno et al. ${ }^{13}$ The largest provider of medical malpractice insurance reduced their premium rates in 2006 by $5 \%$ and did not raise rates in 2004 or 2005 . Yet in prior years they had raised their rates by an average of $20 \%$ per year. ${ }^{13}$ With these statistics in hand, some of the articles do not support or deny that tort reform could have a positive effect on the cost of healthcare, but the majority of the research indicates that tort reform in the form of limiting malpractice payments reduces the frequency and severity of malpractice claims and lowers premiums.

There is a need to change the environment in which practitioners practice. We need a system with more openness about errors and less severe penalties for a misdiagnosis and an environment where we can learn from our mistakes Chawla et $a 1 .{ }^{4}$ There is a need to stress individual accountability. Individual accountability, which differs from the current the current healthcare model of a systems-oriented approach, can lead the way to reduce medical errors and defensive medicine which decrease the cost of healthcare (Luce, 2008). ${ }^{11}$ Some studies believe that we must bolster educational programs to help detour defensive medicine. ${ }^{2}$ Medical schools need to educate future doctors about defensive medicine and the cost associated with its practice. Defensive medicine hazards and more emphasis on standards of care could be implemented into all medical school's curriculum. For example, the Mayo Clinic in Rochester, Minnesota has one of lowest Medicare cost rates per patient in the country (Riley, 2009). ${ }^{6}$ One way they achieve lower healthcare costs is to put the patient and their experiences at the center of medical decisions rather than tort reasons.

\section{Methods}

This literary review focused on research articles using the key words of defensive medicine, tort, reform, and healthcare costs. The review was conducted using the CINAHL database through the library of Southern Illinois University Edwardsville. Limitations were noticed in each study reviewed which included the difficulty measuring defensive medicine. The difference between inappropriate procedures and procedures that were necessary for patient care is not clearly defined in most cases. Also, most of the studies were limited to small areas of the country. The physicians could have a bias opinion in the studies due to their own desire to influence tort reform. 


\section{Summary}

Defensive medicine is tests, procedures, referrals, hospitalizations, or prescriptions ordered by physicians out of fear of being sued. ${ }^{4}$ There needs to be a focus on education patients and physicians alike about the cost implications of defensive medicine. The solution to this problem is not merely a one step answer. It will require across the board changes in the way we educate doctors and patients, or tort reform to introduce caps on malpractice claims. We need to clearly define the standard of care for physicians. ${ }^{4}$ The diagnosing accuracy of physicians does not need to be $100 \%$. Healthcare professionals are being held to a standard of perfection that cannot be reached. Tort reform can play a significant role in not only limiting malpractice insurance but to also deter defensive medicine. Punitive damage and noneconomic damage caps are types of indirect reform and are single most effective method of reducing healthcare cost. ${ }^{2}$ Lower malpractice premiums and decreasing an estimated $\$ 100-180$ billion dollars in defensive medicine costs annually will eventually lower the cost of healthcare for all Americans (Chawla \& Gunderman, 2008). To avoid malpractice, the physicians need to follow standards of care needed for each individual patient. Practitioners need to not let litigation affect the decision making process and send patients home without perform unnecessary testing. Thus, by reducing defensive medicine, we can increase the availability of care, quality of care and significantly decrease the cost of care.

After reviewing literature on defensive medicine, we are left with some ideas for further inquiry. A broader survey of defensive medicine is needed nationwide to determine more accurately the applied costs of this practice. What outcomes can be found from the proposed solutions for defensive medicine? Will there be more negligence by doctors if we have nationwide tort reform? Finally, what happens when the practice of medicine focuses on withholding tests to decrease costs of healthcare rather than caring for patients?

\section{Acknowledgments}

None.

\section{Conflicts of interest}

Author declares that there is no conflicts of interest.

\section{References}

1. Defensive medicine. Merriam-Webster Online Dictionary. 2009.

2. Studdert D, Mello MM, Sage WM, et al. Defensive medicine among high-risk specialist physicians in a volatile malpractice environment. JAMA. 2005;293(21):2609-2617.

3. Anderson G, Hussey P, Frogner B, et al. Health spending in the United States and the rest of the industrialized world: examining the impact of waiting lists and litigation reveals no significant effects on the U.S. health spending differential. Health Affairs. 2005;24(4):903-914.

4. Chawla A, Gunderman RB. Defensive medicine: Prevalence, implications, and recommendations. Acad Radiol. 2008;15(7):948-949.

5. Defensive medicine carries hefty price tag, study finds. 2009.

6. Riley D. Challenges in healthcare reform. Alternative Therapies. 2009;15(4):4-5.

7. Robeznieks A. Wary physicians. Defensive medicine linked to higher costs, less access. Mod Healthc. 2005;35(23):8-9.

8. Sloan FA, Shadle JH. Is there empirical evidence for "Defensive Medicine"? A reassessment. J Health Econ. 2009;28(2):481-491.

9. Fear of malpractice prompts emergency physicians to practice defensive medicine with potential heart attack patients. 2006.

10. De Weese J. Guest editorial. Offensive defensive medicine. Orthopedics. 2006;29(4):296-297.

11. Luce JM. Medical malpractice and the chest physician. Chest. 2008;134(5):1044-1050.

12. Hellinger FJ, Encinosa WE. The impact of state laws limiting malpractice damage awards on health care expenditures. Am J Public Health. 2006;96(8):1375-1381.

13. Karno S, Hoban T, Stalker R, et al. Tort reform: A view from all sides: An expert panel discussion of the issues. Journal of Nursing Law. 2005;10(4):189-200.

14. Gorombei D, Crowell P, Plate L. Medical malpractice tort reform. Journal of Legal Nurse Consulting. 2007;18(1):20-23. 